As regards the articles themselves, it is obviously not possible to review these adequately. The following bare list of the contents, however, will show that there can be few who are interested in any of the branches of physiology who could fail to find an article that appealed to them :

The relation of bioelectric potentials to cell functioning (G. H. Bishop); the physiological effects of radiant energy (H. Laurens); physiological aspects of genetics (A. H. Sturtevant); developmental physiology (E. Witschi); growth (C. E. Palmer and A. Ciocco); temperature regulation (J. C. Scott and H. C. Bazett) ; energy metabolism (T. M. Carpenter); respiration (C. F. Schmidt and J. H. Comroe, jun.) ; physical properties of protoplasm (E. F. Adolph); muscle (W. O. Fenn); the digestive system (J. E. Thomas); liver and bile (W. B. Hawkins); formed elements of the blood (G. M. Higgins) ; heart (C. J. Wiggers and H. D. Green); peripheral circulation (V. E. Hall); electrical activity of the brain $(\mathrm{H} . \mathrm{H}$. Jasper); the autonomic nervous system (D. Sheehan); the special senses, (1) hearing (E. Barany), (2) visual receptors (R. Granit), (3) vibratory sensations and pain (Y. Zotterman); physiological psychology (H. S. Liddell); kidney (L. Leiter) ; metabolic functions of the endocrine glands (S. Soskin); endocrine aspects of the physiology of reproduction (O. Riddle); reproduction of mammals (M. H. Friedman) ; bacterial chemotherapy (E. K. Marshall, Jr.); histamine and anaphylaxis (W. Feldberg); exercise (A. H. Steinhaus).

The paper is matt and restful, and the type and make-up of the best.

\section{Lovatt Evans.}

\title{
MOLECULAR SPECTRA
}

The Identification of Molecular Spectra

By Dr. R. W. B. Pearse and Dr. A. G. Gaydon. Pp. viii $+221+8$ plates. (London: Chapman and Hall, Ltd., 1941.) 42s, net.

$\mathrm{T}$ $O$ identify a given system of bands in molecular spectroscopy, "it has hitherto remained necessary to search through original papers or to calculate the positions of bands from the tables of derived constants. . . . This task is usually tedious and sometimes impossible to one without considerable experience". Drs. Pearse and Gaydon have compiled tables of data which will facilitate the identification of bands occurring in the region $10000 \mathrm{~A}$. to $2000 \mathrm{~A}$. The data, in tabular form, include the recorded systems of diatomic molecules and a certain amount of data on polyatomic molecules; in many instances the authors have extended recorded data by actual measurements. Data on complex organic molecules and on solutions have not been included, but that in no way detracts from the value of the book since it must be obvious that such a compilation must be limited by two main factors, $(a)$ a defined wave-length region, and $(b)$ an enforced limitation of the molecular types to be included.

Essentially the work contains two sections, and their contents can be conveyed most conveniently in the concise statements relating to them in the authors' introduction: "The first section consists of a list of the strongest heads of the more persistent and better known band systems of each molecule in order of wave-length, together with information as to origin, intensity in various sources, and appearance. The second section consists of individual lists of band heads for each system of each molecule, accompanied by notes about the occurrence and appearance of the system, the nature of the electronic transition involved, the vibrational assignment of the bands in the system, and references to the sources of the data. The lists are arranged in alphabetical order of the chemical symbols of the molecules."

The arrangement of the tables is exceptionally clear; band heads are listed in groups of five with a space between each group, which makes their perusal less trying than if they had been printed close on each other line after line. In the second section the appearance and occurrence of each band are described in a crisp and complete manner. Thus the book is lifted from being a mere collection of data. The quoted references to original papers have been selected with care and discrimination. That the book has been compiled from the practical point of view is borne out by an excellent short account (10 pp.) of various points, troublesome to the inexperienced, arising in identification and "not usually dealt with in general text-books"; these "practical hints" are an extremely useful feature, as is also the inclusion of fifty selectedand exceptionally well-reproduced-spectrograms.

The authors have accomplished the tiresome work of collection, selection, compilation and arrangement of the vast amount of data with clarity and skill, and the publishers and printers have done their jobs with equal acceptance. Such a book is needed by workers in this field, and the volume under review can be thoroughly recommended.

W. Rogie Angus. 